\title{
Carnivore conservation at the crossroads
}

\author{
K. UlLas KarAnth and Ravi Chellam
}

$\mathrm{R}$ ecent assessments of the conservation status of mammals present an alarming picture of ongoing declines, emphasizing the urgent need for informed conservation actions. Global analyses show that among terrestrial mammals, many carnivores are the most threatened (Ceballos et al., 2005; Schipper et al., 2008). The 10 studies of mammalian carnivores in this issue of Oryx (pp. 18-9o) provide examples of typical issues of concern from scientific as well as conservation perspectives.

Carnivores comprise 287 extant species in 123 genera belonging to 16 families. Most are threatened by habitat loss and fragmentation, as well as by direct hunting for food, curatives or trophies. Carnivores are also indirectly threatened by human hunters, who deplete a wide taxonomic range of the prey of carnivores, from other mammals to fish, through excessive shooting, snaring, netting or other forms of exploitation (Robinson \& Bennett, 2000). Prey depletion is a particularly insidious threat because its widespread impact is not immediately obvious.

Wild carnivores are charismatic animals that engage human attention for a variety of reasons. Carnivores compete and conflict intensely with humans over food and space across both evolutionary and historical time scales (Inskip \& Zimmermann, 2008), cultural perceptions of carnivores are shaped by factors as diverse as fear, admiration and superstition, and carnivores are valued for the utilitarian values of their meat, pelts or tourism potential.

Mammalian carnivores present challenges to scientists trying to understand them and to conservationists trying to save them. Because of their position high up in the food chain carnivores tend to occur at low population densities. They also tend to be nocturnal, elusive and occasionally dangerous. Because of such traits the majority remain poorly studied. The resulting paucity of reliable knowledge is impeding species recovery efforts, even for conservation flagship species such as the tiger Panthera tigris, lion Panthera leo and wolf Canis lupus. For many carnivores, beyond anatomical descriptions and coarse range maps we still lack basic knowledge of diet, social organization, community ecology, population biology and genetics.

Over the last 2-3 decades the focus of carnivore research appears to have shifted from earlier species-oriented ecology and behavioural studies towards attempts to infer broader macro-ecological or evolutionary patterns through meta-analyses of pre-existing data-sets (Carbone \& Gittleman, 2002). However, most meta-analyses provide broad, post hoc generalizations, often based on ad hoc statistical

K. Ullas Karanth and Ravi Chellam Wildlife Conservation Society, Bangalore, India. E-mail ukaranth@gmail.com

methods. Consequently, the need for ecological knowledge of individual species and conservation contexts remains unfulfilled. We submit that carnivore science and conservation could benefit greatly from a move towards studies that are based on biological models generated a priori and tested against rigorously collected field data using modern likelihood-based or Bayesian inferential frameworks (Bolker, 2008; Royle \& Dorazio, 2008). We believe such a shift would also be helpful in making conservation decisions in an adaptive management framework and in advancing the science of carnivore studies.

Larger and more predatory carnivore species within the families Felidae, Canidae and Ursidae appear to be suffering the severest population declines and range contractions (Ceballos et al., 2005; Schipper et al., 2008). Studies show that human intolerance of such predatory carnivores is often, however, based on misconceptions about the potential risk they pose to livestock and humans (Treves \& Karanth, 2003). Additionally, several carnivore species that are adapted to unique ecological niches or a narrow range of habitats, or have narrow diets, such as the bush dog Speothos venaticus, are also threatened.

Populations of vulnerable carnivore species are unable to persist under human land uses that engender conflicts over habitat, space or prey. Mitigation of these conflicts through measures such as exclusion barriers, guarding, financial compensation or elimination of so-called problem animals, is complex and difficult (Treves \& Karanth, 2003). Historically, a common consequence of such conflict has been the elimination of carnivores from human-dominated landscapes.

Therefore, while post hoc mitigation of conflicts through innovative responses are urgently needed, establishment and maintenance of large nature reserves protected against incompatible human uses remains a key conservation requirement for many carnivore species. Well-known examples of this approach come from India's recovery projects for tigers and the last surviving population of Asiatic lions. These projects have relied on large-scale, incentive-driven relocation of human settlements to create the relatively large, intact habitats required by these species (Karanth \& Gopal, 2005). Unfortunately, in the prevailing context of the global conservation-development paradigm, with its apparent faith in the potential for peaceful coexistence of biodiversity and sustainable use, the strategy of using large reserved areas for carnivore conservation is being downplayed worldwide.

On a more positive note, although carnivores face increasing threats, many species do possess demographic traits such as early reproduction, large litter sizes and high 
fecundity that make them relatively resilient. Red fox Vulpes vulpes, for example, has one of the largest distributional range of all land mammals. Some carnivore species have even become exotic invasive nuisances, negatively impacting native fauna (Ibarra et al., 2008).

Interestingly, some rare and threatened carnivores appear to be benefiting from recent land-use and cultural changes. Such is the case of the puma Puma concolor in North America in places where farms have given way to woodlands, and of lynxes Lynx lynx, wolves and brown bears Ursus arctos in Europe, where the rise of anti-hunting sentiments and animal welfare concerns have reinforced recent range recoveries.

In India, because of higher levels of traditional cultural tolerance, leopards Panthera pardus, wolves, sloth bears Melursus ursinus, striped hyenas Hyena hyena and a host of smaller carnivore species survive amidst high human population densities across wide sweeps of agricultural landscapes. Furthermore, tourism and safari hunting, driven by fascination for larger carnivores such as lions and leopards, is shifting land use in parts of Africa, driving the expansion of the habitats of these species. Television documentaries with huge global audiences are creating a new class of urban conservationists that champion the cause of tigers threatened by bone trade or polar bears Ursus maritimus imperilled by melting sea-ice.

Nevertheless, increasing human population densities and the consequent demand for food and natural resources will rapidly erode and fragment remaining carnivore habitats. Driven by the same socio-economic forces, global climate change poses an even greater impending threat. However, in some areas at least, the same socio-economic growth also appears to be moving people from remote wild areas to urban growth centres, thereby reducing hunting and habitat related pressures on carnivores. Substitution of wild meat in local diets by domestic meat and poultry can reduce overhunting of natural prey, thus mitigating a potentially critical threat to many carnivore species. Cultural changes appear to promote greater tolerance or even support for protection of carnivores and their habitats, although counter examples to this trend, such as the increasing demand for carnivore body parts in traditional oriental medicine, also exist.

In our rapidly changing world the conservation of carnivores now stands at the crossroads. How effectively scientists, conservationists, governments and society at large will study, understand, collaborate and move forward to meet the ecological needs of these mammals will determine where and how many species and populations will survive. Wherever we fall short these marvellous animals-both products and shapers of life on earth-will become just road kills on the highway of human historical progress.

\section{References}

Bolker, B.M. (2008) Ecological Models and Data in R. Princeton University Press, Princeton, USA.

Carbone, C. \& Gittleman, J.L. (2002) A common rule for scaling carnivore density. Science, 295, 2273-2276.

Ceballos, G., Erlich, P.R., Soberon, J., Salazar, I. \& Fay, J.P. (2005) Global mammal conservation: What must we manage? Science, 309, 603-607.

ibarra, J.T., Fasola, L., Macdonald, D.W., Rozzi, R. \& BonACIC, C. (2008) Invasive American mink Mustela vison in wetlands of the Cape Horn Biosphere Reserve, southern Chile: what are they eating? Oryx, 43, 87-90.

InSKip, C. \& ZimmermanN, A. (2008) Human-felid conflict: a review of patterns and priorities worldwide. Oryx, 43, 18-34.

Karanth, K.U. \& Gopal, R. (2005) An ecology-based policy framework for human-tiger coexistence in India. In People and Wildife: Conflict or Coexistence? (eds R. Woodroffe, S. Thirgood \& A. Rabinowitz), pp. 373-387. Cambridge University Press, Cambridge, UK.

Robinson, J.G. \& BennetT, E.L. (2000) Hunting for Sustainability in Tropical Forests. Columbia University Press, Irvinton, USA.

Royle, J.A. \& Dorazio, R.M. (2008) Hierarchical Modeling and Inference in Ecology: The Analysis of Data from Populations, Metapopulations and Communities. Academic Press, San Diego, USA.

Schipper, J., Chanson, J.S., Chiozza, F., Cox, N.A., Hoffmann, M., Katariy A, V. et al. (2008) The status of the world's land and marine mammals: diversity, threat and knowledge. Science, 322, 225-230.

Treves, A. \& Karanth, K.U. (2003) Human-carnivore conflict and perspectives on carnivore management worldwide. Conservation Biology, 17, 1491-1499.

\section{Note from the Editor - www.oryxthejournal.org}

For a conservation journal that promotes better conservation management and practice, how widely do our responsibilities range? In the Oryx Editorial Office we feel that our responsibility to help build capacity for conservation does not begin with the receipt of a manuscript nor end when a quarterly issue is produced. We have therefore been seeking ways that the journal can expand and improve its support to conservationists. Oryx-The International Journal of Conservation therefore now has a dedicated website at http://www.oryxthejournal.org

The new website provides recommendations for the best free analysis and writing tools, advice on accessing Oryx in developing countries or countries with emerging economies, help with submitting an article, an interactive map illustrating the broad geographical range of articles published in the journal, a stunning Gallery of research photographs provided by authors, snippets from the Oryx Archive, and much more besides. Please browse the website and tell us how it could be further developed. If there are further resources that we could include, please let us know. 